\title{
The assessment of population exposure to chlorination by-products: a study on the influence of the water distribution system
}

\author{
Christelle Legay ${ }^{1}$, Manuel J Rodriguez ${ }^{1 *}$, Jean Baptiste Sérodes ${ }^{2}$, Patrick Levallois ${ }^{3}$
}

\begin{abstract}
Background: The relationship between chlorination by-products (CBPs) in drinking water and human health outcomes has been investigated in many epidemiological studies. In these studies, population exposure assessment to CBPs in drinking water is generally based on available CBP data (e.g., from regulatory monitoring, sampling campaigns specific to study area). Since trihalomethanes (THMs) and haloacetic acids (HAAs) are the most documented CBP classes in drinking water, they are generally used as indicators of CBP exposure.

Methods: In this paper, different approaches to spatially assign available THM and HAA concentrations in drinking water for population exposure assessment purposes are investigated. Six approaches integrating different considerations for spatial variability of CBP occurrence within different distribution systems are compared. For this purpose, a robust CBP database (i.e., high number of sampling locations selected according to system characteristics) corresponding to nine distribution systems was generated.

Results and conclusion: The results demonstrate the high impact of the structure of the distribution system (e.g., presence of intermediary water infrastructures such as re-chlorination stations or reservoirs) and the spatial variability of CBPs in the assigned levels for exposure assessment. Recommendations for improving the exposure assessment to CBPs in epidemiological studies using available CBP data from water utilities are also presented.
\end{abstract}

\section{Background}

In recent decades, various epidemiological studies have been conducted to determine the relationship between chlorination by-products (CBPs) and different health outcomes (e.g., cancers and reproductive outcomes) [1-4]. Since trihalomethanes (THMs) and haloacetic acids (HAAs) are the most prevalent and documented CBP compounds in drinking water, they are generally considered as indicators of CBP exposure in epidemiological investigations.

In epidemiological studies focusing on THMs and HAAs in drinking water and human health outcomes, exposure misclassification can occur through the assessment of population exposure to these compounds and especially in the estimation of their levels in residential tap water [5-7]. In fact, several parameters varying in

\footnotetext{
* Correspondence: manuel.rodriguez@esad.ulaval.ca

'École supérieure d'aménagement du territoire, Université Laval, Pavillon

Antoine Savard, Québec City, QC., G1K 7P4, Canada

Full list of author information is available at the end of the article
}

time and space, such as water source characteristics, operational parameters during treatment and distribution system specificities, influence THM and HAA occurrence in distribution systems [8]. This temporal and spatial variability within drinking water systems could result in inaccuracies in the estimation of their levels.

Generally speaking, it is difficult and expensive to obtain sufficient THM and HAA data representing these spatio-temporal variations in different distribution systems through direct measurements in residential tap water and based on a high sampling frequency. As a result, alternative data are used in epidemiological investigations on population exposure assessment. In fact, the majority of these studies use data available through regulatory compliance on CBPs in drinking water for which THMs and HAAs (the latter only in United States (US)) are routinely measured [9-17]. With some differences according to region or country, regulatory compliance generally requires a minimum of quarterly CBP 
measurements at one to four sampling locations per distribution system [18-20].

Given the potential spatial variability of THM and HAA occurrence within distribution systems, a major challenge facing epidemiological studies based on available THM and HAA concentrations in tap water is to spatially assign these data to subjects in order to be the most representative of real exposure. In the studies where data are available only at a single location in the distribution system, these data are assigned directly to the subject's residential tap water. However, in the case where more than one location in the subject's distribution system is sampled, different approaches are applied to estimate THM and HAA levels in the subject's residential tap water. The distribution systemwide average of THM and HAA data is used for exposure assessment in most epidemiological studies $[9,11,13-15,21]$. Other studies consider THM and HAA data from the closest sampling location within the distribution system to the subject's residence as representative of the subject's exposure [16,22]. Different methods to assign available data to subjects are also applied, such as the use of the distribution and statistical variance of THM and HAA levels in distribution systems [22,23]. The more accurate approach is based on the assignment to the subjects of data from the sampling location in the distribution system with hydraulic characteristics similar to the target location $[10,12]$. However, this type of information is rarely available. According to the degree of spatial variability of THMs and HAAs and the subject's residential location within distribution systems, these approaches could involve misclassifications in exposure assessment [13,22-24]. In fact, distribution system characteristics that influence THM and HAA occurrence, such as system size and the presence of intermediary water infrastructures to the water treatment plant (i.e., rechlorination station or reservoir), are generally not considered. As a result, data used to assess the THM and HAA levels in the subject's tap water from a sampling location in the subject's distribution system are not necessarily representative of the subject's residential water quality (e.g., with different hydraulic characteristics and not being supplied by the same direct water infrastructure) [7].

The main objective of this paper is to investigate and compare different spatially-based approaches to assign available THM and HAA concentration data to subjects involved in epidemiological studies. These approaches integrate different considerations of the variability of THM and HAA occurrence within distribution systems. In addition, for each method, the impact of distribution characteristics (i.e., system size and structure) on the estimation of THM and HAA levels in the subject's tap water is studied. For the study, an important database in terms of population under study and CBP measurements was used to test six different approaches. The results from the assignment of THM and HAA data to the subjects following each approach are compared. Finally, recommendations are made to minimize exposure misclassifications associated with spatial variability of THMs and HAAs in drinking water in the assignment of their levels to the subject's residential tap water.

\section{Methods}

\section{Case under study}

This study was conducted with nine distribution systems of the greater area of Québec City (Province of Quebec, Canada). Five distribution systems denoted AR, DE, LE, QC and STF supply Québec City (approximately 480,000 inhabitants) and four systems denoted CH, LS, LZ and SR supply the city of Lévis (approximately 120,000 inhabitants). These systems are illustrated in Figure 1 and their main characteristics are presented in Table 1. Each distribution system is supplied by surface water and uses free chlorine for primary or secondary disinfection (that generally follows physico-chemical water treatment such as coagulation, sedimentation and filtration). However, characteristics of the supply system such as the type of water source (e.g., river and lake), water treatment processes, population served, system size and hydraulic conditions vary from one system to another. As shown in Table 1, for a specific distribution system, the population might be served by a different water infrastructure, either directly by the water treatment plant or through a re-chlorination station or reservoir. Each area served by a different water infrastructure within the same distribution system is defined as a subsystem. In the case where a distribution system is directly supplied only by the treatment plant, the presence of a single sub-system is assumed. The nine distribution systems under study differ also in the number and type of sub-systems (Table 1).

The region under study is subject to important climatic variations during the year, with average air ambient temperature ranging from $-15^{\circ} \mathrm{C}$ to $+24^{\circ} \mathrm{C}$ and different lengths of seasons (i.e., long winters and relatively short summers). These temporal fluctuations involve important temporal variations in the quality of raw and treated water.

\section{Description of data \\ Population under study}

The population under study involved subjects from a case-control epidemiological investigation on intrauterine growth retardation (IUGR) carried out in the greater area of Québec City during 2006-2008 (Levallois et al. 2009; personal communication). The subjects were 


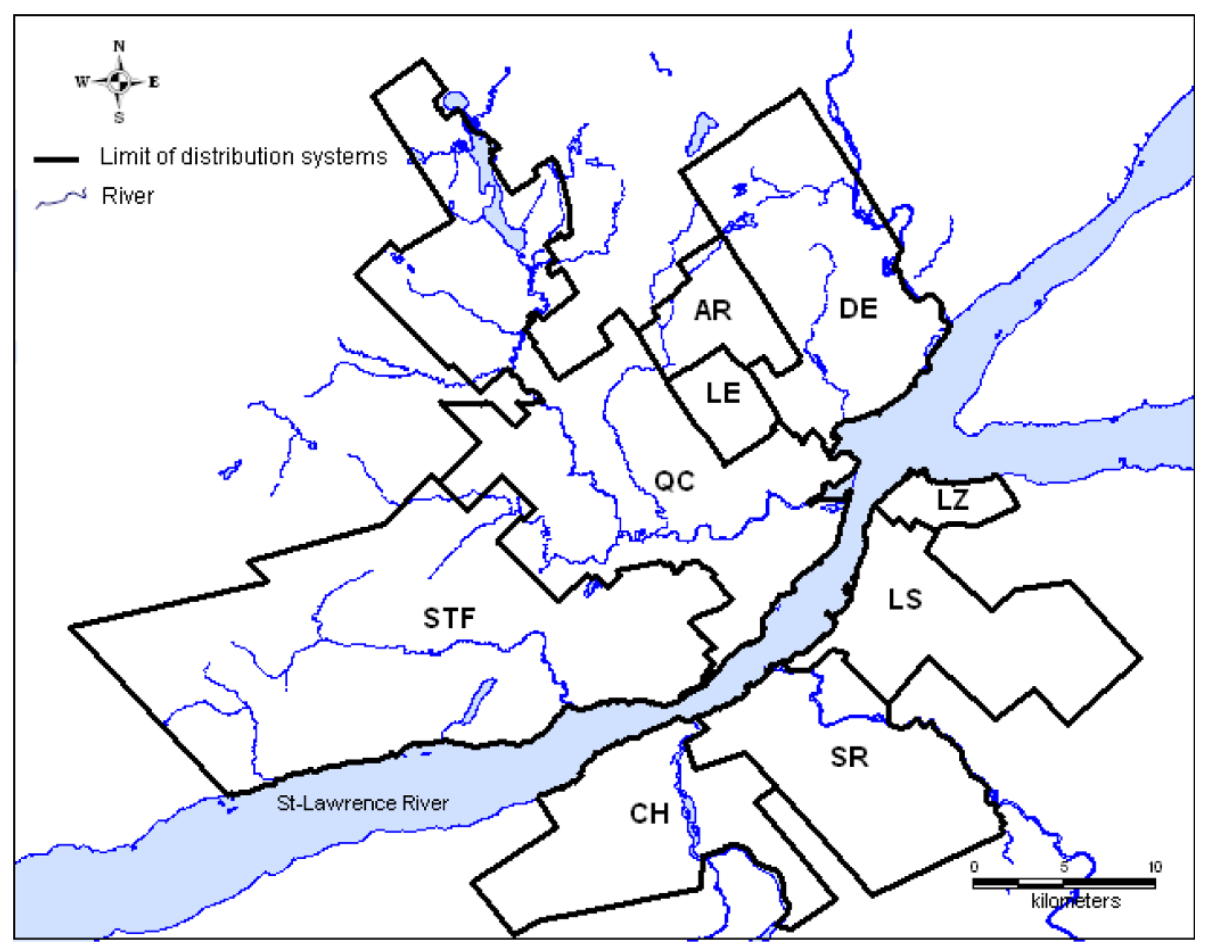

Figure 1 Location of the nine distribution systems under study.

women who each delivered a single live infant for whom exposure to CBPs in drinking water during each pregnancy quarter was studied. This paper is restricted to women living in a single residence located in one of the nine systems studied during their entire pregnancy period. Moreover, only pregnancy trimesters comprised between April 2006 and April 2008 were included in the analysis. By means of a phone questionnaire carried out approximately one to two months after the women gave birth, information on their pregnancy residence address (i.e., house number, street, municipality, and postal code) was obtained. The geographical location of each

Table 1 Characteristics of the nine distribution systems under study

\begin{tabular}{|c|c|c|c|c|c|c|}
\hline $\begin{array}{l}\text { Distribution } \\
\text { system }\end{array}$ & Water source & $\begin{array}{l}\text { Flow rate }\left(\mathrm{m}^{3} /\right. \\
\text { day) }\end{array}$ & $\begin{array}{l}\text { Number of sub- } \\
\text { systems }\end{array}$ & Particular characteristics & $\begin{array}{l}\text { Number of sampling } \\
\text { sites }\end{array}$ & $\begin{array}{l}\text { Number of } \\
\text { subjects }^{\mathrm{a}}\end{array}$ \\
\hline$A R$ & $\begin{array}{l}\text { Des Roches } \\
\text { Lake. }\end{array}$ & $\pm 9,000$ & 3 & $\begin{array}{l}\text { Re-chlorination stations or } \\
\text { reservoirs. }\end{array}$ & 3 & 76 (194) \\
\hline $\mathrm{DE}$ & $\begin{array}{l}\text { Montmorency } \\
\text { River. }\end{array}$ & $\pm 33,000$ & 5 & $\begin{array}{l}\text { Re-chlorination stations or } \\
\text { reservoirs. }\end{array}$ & 5 & $188(493)$ \\
\hline LE & $\begin{array}{l}\text { Sept Ponts } \\
\text { River. }\end{array}$ & $\pm 19,000$ & 1 & None. & 2 & $91(249)$ \\
\hline QC & St. Charles Lake. & $\pm 145,000$ & 4 & $\begin{array}{l}\text { Re-chlorination stations or } \\
\text { reservoirs. }\end{array}$ & 10 & $549(1,457)$ \\
\hline STF & $\begin{array}{l}\text { St. Lawrence } \\
\text { River. }\end{array}$ & $\pm 69,000$ & 5 & $\begin{array}{l}\text { Re-chlorination stations or } \\
\text { reservoirs. }\end{array}$ & 6 & $189(498)$ \\
\hline $\mathrm{CH}$ & $\begin{array}{l}\text { Chaudiere } \\
\text { River. }\end{array}$ & $\pm 13,000$ & 6 & $\begin{array}{l}\text { Re-chlorination stations or } \\
\text { reservoirs. }\end{array}$ & 8 & $117(309)$ \\
\hline LS & $\begin{array}{l}\text { St. Lawrence } \\
\text { River. }\end{array}$ & $\pm 24,000$ & 2 & $\begin{array}{l}\text { Re-chlorination stations or } \\
\text { reservoirs. }\end{array}$ & 5 & $120(316)$ \\
\hline LZ & $\begin{array}{l}\text { St. Lawrence } \\
\text { River. }\end{array}$ & $\pm 11,000$ & 2 & $\begin{array}{l}\text { Re-chlorination stations or } \\
\text { reservoirs }\end{array}$ & 3 & $44(112)$ \\
\hline$S R$ & $\begin{array}{l}\text { St. Lawrence } \\
\text { River. }\end{array}$ & $\pm 10,000$ & 2 & $\begin{array}{l}\text { Re-chlorination stations or } \\
\text { reservoirs. }\end{array}$ & 4 & $96(251)$ \\
\hline
\end{tabular}

\footnotetext{
${ }^{a}$ The number of pregnancy trimesters studied is shown into parenthesis
} 
subject's residence in the appropriate system and subsystem under study was determined using a geographical information system (GIS) supported by MapBasic Version 8.0 that integrates residential postal codes (with Platinum Postal Suite ${ }^{\text {TM }}$ 2008.3).

This paper focuses specifically on the spatial assignment of CBP data in residential tap water for each subject. The spatial variability of THMs and HAAs within distribution systems can be influenced by temporal variations (i.e., seasons, months) of water quality [25]. In order to minimize the temporal impact of the occurrence of THMs and HAAs on the subject's exposure assessment obtained from the different spatial approaches, multiple exposure periods were investigated for each subject. These periods corresponded to different trimesters of their pregnancy (varying from two to three according to the subjects) and thus to different seasonal periods of the year. A total of 3,879 pregnancy trimesters for 1,470 subjects were considered in this investigation (Table 1).

\section{CBP data collection}

The estimation of THM and HAA levels in a subject's tap water during each exposure period under study was based on data from sampling campaigns tailor-made for the epidemiological study on IUGR. Between April 2006 and April 2008, monthly sampling campaigns for THM and HAA measurements were carried out at $46 \mathrm{sam}$ pling sites spatially distributed in the nine distribution systems. The number and location of the sampling sites were specifically selected according to the size of the population served and system structure (e.g., according to system size and number of sub-systems). For the nine distribution systems, at least one sampling site was located in each sub-system. The distribution of the number of sampling sites among the nine systems is also presented in Table 1.

For THMs, the four following compounds were analyzed: chloroform, bromodichloromethane (BDCM), dibromochloromethane (DBCM) and bromoform. The sum of these four compounds represents the total THMs (TTHMs). The nine individual HAAs were also analyzed: monochloroacetic (MCAA), dichloroacetic (DCAA), trichloroacetic (TCAA), monobromoacetic (MBAA) and dibromoacetic (DBAA), tribromoacetic (TBAA), bromochloroacetic (BCAA), dibromochloroacetic (DBCAA), bromodichloroacetic (BDCAA) acids. HAA9 refers to the sum of these nine compounds. The sampling and analytical procedures applied to characterize the THM and HAA levels are described in a previous study [26]. Measurements below their detection limit for each compound under study were considered equal to zero [22,23]. In the rest of paper, CBPs refer to TTHMs and HAA9.

\section{Assessment of CBP levels in the subject's tap water}

Six different methods were applied and compared to estimate CBP levels in the subject's drinking water. In the six methods denoted A to $F$, the spatial variability of THMs and HAAs in drinking water was integrated differently. These methods differ in various ways: geographical scale considered (i.e., the entire distribution system or the sub-system), number of sampling sites considered and location of sampling sites associated with the subject's residence. Moreover, the metric applied to assign the CBP data from sampling site(s) selected to the subjects (i.e., direct assignment of CBP data, average or use of weighting factor) also differs according to the methods. The metric generally depends on the number of sampling sites selected. Since the geographical scale significantly influences the other factors (i.e., the number and the location of sampling sites), the different methods under study are presented according to the geographical scale under consideration.

\section{Methods applied at the sub-system scale}

In four of the six CBP level assessment methods under study, only the sampling site(s) supplied by the same direct water infrastructure of the subject's residence (i.e., located in the subject's sub-system) were considered: methods A, B, C and D.

Method A: The two sampling sites closest to the subject's residence were used. In order to integrate the potential spatial variations of CBP occurrence within sub-systems, a weighting factor was applied at these two sampling sites. The weighting factors were estimated on the basis of the distance between the subject's residence and the two specified sampling sites. As a result, for each of the sampling sites considered, the weighting factors (WF) were calculated as following:

$$
\begin{aligned}
& W F_{P 1}=1-\left(\frac{d_{P 1}}{d_{P 1}+d_{P 2}}\right) \\
& W F_{P 2}=1-\left(\frac{d_{P 2}}{d_{P 1}+d_{P 2}}\right)
\end{aligned}
$$

where $P_{1}$ and $P_{2}$ are the first and the second specified sampling sites respectively, that represent CBP exposure of a subject, and d denotes the distance between the specified sampling site and the subject's residence (without unit: distances were standardized from coordinates).

Method B: The average of CBP data from the two closest sites to the subject's residence was carried out (i.e., method A without weighting factor) and assigned to the subjects.

Method C: CBP data from the closest sampling to the subject's residence were directly assigned to the subjects. 
Method D: The average of CBP data from all sampling sites located in the sub-system was carried out and assigned to the subjects.

In various sub-systems, a single location was sampled. As a result, irrespective of the method applied at the sub-system scale, the CBP data from this site were considered to represent exposure for subjects located in the sub-system.

\section{Methods applied at the distribution system-scale}

The two remaining methods (methods E and F) considered sampling sites located in the same distribution system of the subject's residence.

Method E: CBP data from the closest sampling site to the subject's residence were assigned directly to the subjects (i.e., without considering the presence of an intermediary water infrastructure). This approach has also been applied to assign CBP data to the subjects in several epidemiological studies $[16,22]$.

Method F: The average of CBP data from all sampling sites located in the distribution system was calculated and assigned to the subjects. This method represents the usual spatial approach applied to assign available CBP data to the subjects in epidemiological studies [9,11,13-15].

In these methods applied at the two geographical scales, the road distance from the subject's residence to a specific sampling site was used as an indicator of proximity (not used in the methods D and F). However, the systematic correlation between the distance to a sampling site and the CBP levels was not demonstrated [22]. Since this type of proximity indicator was available (contrary to the precise water residence time in the pipes), it was used in the CBP level assessment methods presented herein.

For each method, the estimation of CBP levels in the subject's tap water through the assignment of available CBP data in this study was performed using SAS Version 9.2 [27].

\section{Data analysis}

In order to compare CBP levels between years, sub-systems and systems, several statistical tests were carried out. Since TTHM and HAA9 levels were not always distributed in accordance with the Gaussian Law, nonparametric tests were used. As a result, the Kolmogorov-Smirnov $\mathrm{Z}$ test was applied when two independent samples were compared and the Kruskal-Wallis $\mathrm{H}$ test when more than two independent samples were compared. Each of these tests was carried out using the statistical significance level $\rho<0.05$ (SPSS Version 13.0).

Usually, in epidemiological studies, the relationship between adverse health outcomes and CBPs in drinking water is evaluated using categorical exposure variables. The categories of CBP exposure are generally based on
CBP levels measured in the area under study and more precisely on CBP level percentiles [14,17,21]. As a result, for each of the six methods under study, the subjects were classified in TTHM and HAA9 exposure categories according to the estimation of CBP levels in their residence drinking water obtained from the specific method. TTHM and HAA9 exposure categories were based, as thresholds, on quartiles of their levels measured in the drinking water distribution systems. A first analysis including all the distribution systems was carried out (i. e., the cut-points based on the CBP levels measured in all the distribution systems). In order to evaluate the impact of the methods according to the characteristics of the distribution system, analyses for each individual system were also carried out with exposure categories specific to each system.

Kappa statistics were estimated to compare the classification of the subjects in TTHM and HAA9 exposure categories obtained from the six methods. The Kappa coefficient represents the agreement between two methods $[28,29]$. Given the ordered nature of outcomes (i.e., exposure categories), weighted kappa coefficients $(\kappa)$ were estimated with a linear weighting scheme [30]. For each compared pair-method (e.g., methods A and B, methods $\mathrm{A}$ and $\mathrm{C}$, methods $\mathrm{B}$ and $\mathrm{C}$ ), $\kappa$ value was calculated using the statistical level $\rho<0.05$ (STATA Version 9.0). The agreement between two methods was considered as "poor" for $\kappa \leq 0.20$; "Fair" for $0.21 \leq \kappa \leq$ 0.40; "moderate" for $0.41 \leq \kappa \leq 0.60$; "substantial" for $0.61 \leq \kappa \leq 0.80$; and "almost perfect" with $0.81 \leq \kappa \leq$ $1.00[31]$.

\section{Results and discussion}

\section{CBP occurrence in the area under study}

Table 2 presents the TTHM and HAA9 levels measured during the 2006-2008 period in the nine distribution systems under study. As shown in this table, average CBP levels during the entire study period differed from one distribution system to another. In fact, the highest average TTHM levels were found for the LE, AR and DE systems. The regulatory standard for TTHMs is 80 $\mu \mathrm{g} / \mathrm{L}$ in the Province of Quebec and in US $[18,20]$. Average TTHM levels were not consistent with regulatory compliance for the DE system in 2006-2007 and in 2007-2008 and for the AR and LE systems in 20072008. Lower TTHM concentrations were observed for the other systems and principally for the QC and STF systems. A similar pattern was observed for HAA9 with levels below those measured for TTHM, except for the AR, DE and QC systems (Table 2). Levels above the US standard for HAA5 (which is the sum of MCAA, DCAA, TCAA, MBAA and DBAA) of $60 \mu \mathrm{g} / \mathrm{L}$ [20] were found (data not shown) for the same systems and the same periods as the TTHMs. The temporal variations of 
Table 2 CBP levels measured in each distribution system during 2006-2008

\begin{tabular}{|c|c|c|c|c|c|c|c|c|c|c|}
\hline Distribution system & & TTP & $\mathrm{M}(\mu \mathrm{g} / \mathrm{L})$ & & & & & $9(\mu \mathrm{g} / \mathrm{L})$ & & \\
\hline & $25^{\text {th }}$ Perc. $^{\text {a }}$ & $50^{\text {th }}$ Perc. & $75^{\text {th }}$ Perc. & Mean & $S D^{b}$ & $25^{\text {th }}$ Perc. & $50^{\text {th }}$ Perc. & $75^{\text {th }}$ Perc. & Mean & SD \\
\hline$A R$ & 31.1 & 67.4 & 117.5 & 76.6 & 50.0 & 36.2 & 60.4 & 100.9 & 74.9 & 50.0 \\
\hline $\mathrm{DE}$ & 61.8 & 99.1 & 162.7 & 111.3 & 61.2 & 73.5 & 113.5 & 145.1 & 115.2 & 52.9 \\
\hline LE & 43.4 & 61.8 & 96.7 & 75.2 & 43.0 & 43.5 & 56.4 & 77.4 & 66.5 & 33.7 \\
\hline QC & 15.1 & 22.5 & 34.0 & 26.0 & 14.5 & 16.7 & 23.0 & 31.6 & 25.3 & 11.3 \\
\hline STF & 26.8 & 35.4 & 47.3 & 38.1 & 15.0 & 21.6 & 28.6 & 36.1 & 29.2 & 10.5 \\
\hline $\mathrm{CH}$ & 30.0 & 45.5 & 79.1 & 57.0 & 33.3 & 34.9 & 45.4 & 58.0 & 48.4 & 19.4 \\
\hline LS & 29.9 & 40.3 & 53.4 & 42.1 & 16.7 & 24.7 & 31.9 & 38.9 & 32.3 & 9.9 \\
\hline LZ & 32.1 & 39.4 & 60.8 & 46.8 & 20.2 & 30.4 & 34.9 & 41.4 & 36.0 & 9.1 \\
\hline$S R$ & 39.2 & 57.6 & 75.4 & 59.4 & 23.7 & 31.8 & 43.4 & 55.6 & 45.6 & 17.4 \\
\hline
\end{tabular}

${ }^{\text {aPerc: }}$ percentile

${ }^{\mathrm{b}} \mathrm{SD}$ : standard deviation

TTHM and HAA9 occurrence in drinking water were also investigated. To achieve this, average CBP levels were compared for each distribution system for 20062007 and 2007-2008. In the case of HAA9, statistically significant different levels were observed between the two years for the DE, LZ and SR systems. Only two systems (LE and SR) presented a statistically significant difference between the two average annual TTHM levels.

As shown in Table 2, the distribution of TTHM and HAA9 levels (i.e., represented by percentile and standard deviation values) found for each distribution system during the entire period is widespread. Moreover, this phenomenon is more obvious in the AR, DE, LE, SR and $\mathrm{CH}$ systems. One explanation for these results was the presence of a substantial temporal variability of water quality during the year in the Québec region. For example, Figures 2a-b illustrate the statistically significant seasonal variations of TTHM levels in 2007-2008. A comparable temporal pattern of TTHM variability was observed for the nine distribution systems for which higher TTHM levels were measured during summer and fall. In the case of HAA9 occurrence, statistically significant temporal variations were also obtained (Figures 3ab). However, the temporal pattern differed between the distribution systems.

Another explanation for the widespread distribution of CBP levels measured for the distribution systems is the presence of the spatial variability of CBP occurrence within these systems. Figures 4 and 5 present the quarterly average of TTHM and HAA9 levels measured in all sampling sites during 2007, respectively. These figures confirm the statistically significant differences of average CBP levels between the sub-systems of each distribution system (except for the LS system). Figures 4a$\mathrm{d}$ also illustrate the variability within sub-systems of TTHM levels for most systems. The spatial variability between and within sub-systems was also observed for
HAA9, but with different patterns (Figures 5a-d). The spatial variability of TTHM and HAA9 levels confirms the influence of the distribution system structure on CBP occurrence, such as the number and the nature of sub-systems (i.e., the type of water supply infrastructure) and the sub-system location within the systems.

In addition, Figures 4 and 5 show that the variability pattern of CBP occurrence within distribution system differed according to the quarter under study. For example, the spatial variability of TTHM levels within distribution systems was relatively low during the $1^{\text {st }}$ quarter, which corresponds to the winter (Figure 4a), as compared to the $3^{\text {rd }}$ quarter (Figure 4c). Figures $5 \mathrm{a}$-d also demonstrate the difference of spatial variations of HAA9 occurrence within distribution systems between the quarters of the year. Combined with the presence of monthly variations of TTHM and HAA9 occurrence (Figures 2 and 3), these results justify the study of more than one pregnancy trimester for each subject.

\section{Comparison of methods used to spatially assign CBP data to the subjects}

The previous section demonstrated the high spatial variability of TTHM and HAA9 occurrence within distribution systems, with the degree dependant mainly on structural characteristics and treated water quality. The non-consideration of CBP variations within distribution systems in the assessment of CBP levels in the subject's tap water based on available data in epidemiological studies could result in exposure assessment misclassifications.

For each method, the subjects were classified in CBP exposure categories according to the estimated CBP levels in their residential tap water. The classification of the subject's exposure to TTHM and HAA9 specific to each method was first carried out on a regional basis, considering the entire area under study (i.e., the nine 


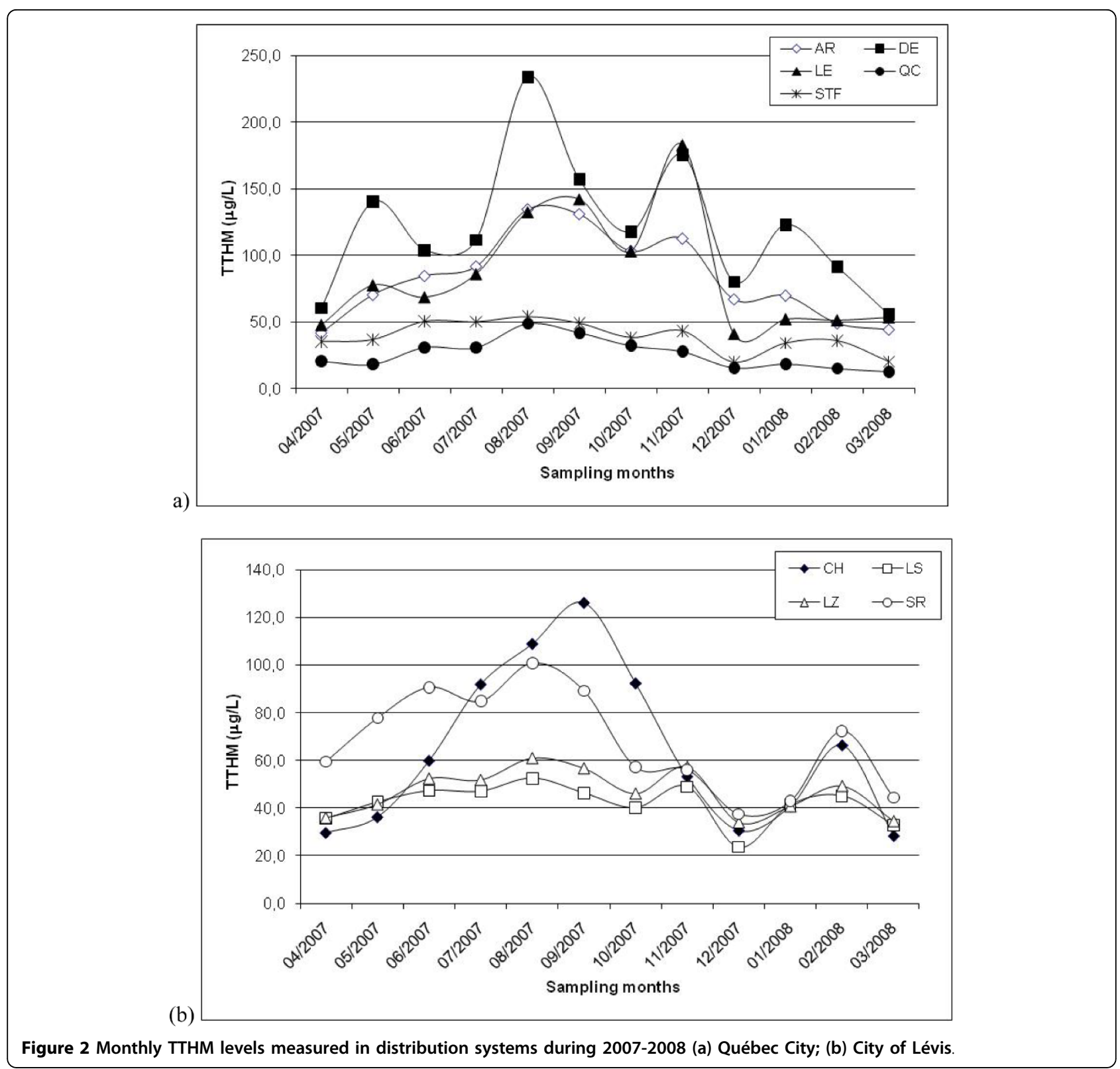

distribution systems). Since the range of measured CBP levels and the degree of spatial variability of their occurrence differed from one distribution system to the other, the classification of the subject's exposure by the six methods also was carried out specifically for each individual distribution system.

\section{Comparison of methods considering the entire area under study}

As described in Section 2.4, the four following TTHM exposure categories were created according to TTHM levels measured in the entire area: $\leq 26.8 \mu \mathrm{g} / \mathrm{L}\left(1^{\text {st }}\right) ; 26.9$ to $40.9 \mu \mathrm{g} / \mathrm{L}\left(2^{\text {nd }}\right) ; 41.0$ to $67.6 \mu \mathrm{g} / \mathrm{L}\left(3^{\text {rd }}\right) ; \geq 67.7 \mu \mathrm{g} / \mathrm{L}\left(4^{\text {th }}\right)$. In the same way, four HAA9 exposure categories were obtained: $\leq 25.7 \mu \mathrm{g} / \mathrm{L}\left(1^{\text {st }}\right) ; 25.8$ to $36.5 \mu \mathrm{g} / \mathrm{L}\left(2^{\text {nd }}\right) ; 36.6$ to
$53.5 \mu \mathrm{g} / \mathrm{L}\left(3^{\text {rd }}\right) ; \geq 53.6 \mu \mathrm{g} / \mathrm{L}\left(4^{\text {th }}\right) . \kappa$ values representing the agreement between the classification of the subjects in the TTHM and HAA9 exposure categories obtained from the six assignment methods are presented in Table 3.

As shown in Table 3, substantial levels of agreement between the methods applied at different space scales were observed for TTHMs and HAA9. These results are explained mainly by the high spatial variability of CBP occurrence in distribution systems. Consequently, the type of space scale considered in the CBP data assignment method has an impact on the subject's exposure classification.

Table 3 demonstrates that the spatial variability of CBPs in drinking water also involves differences in the exposure 


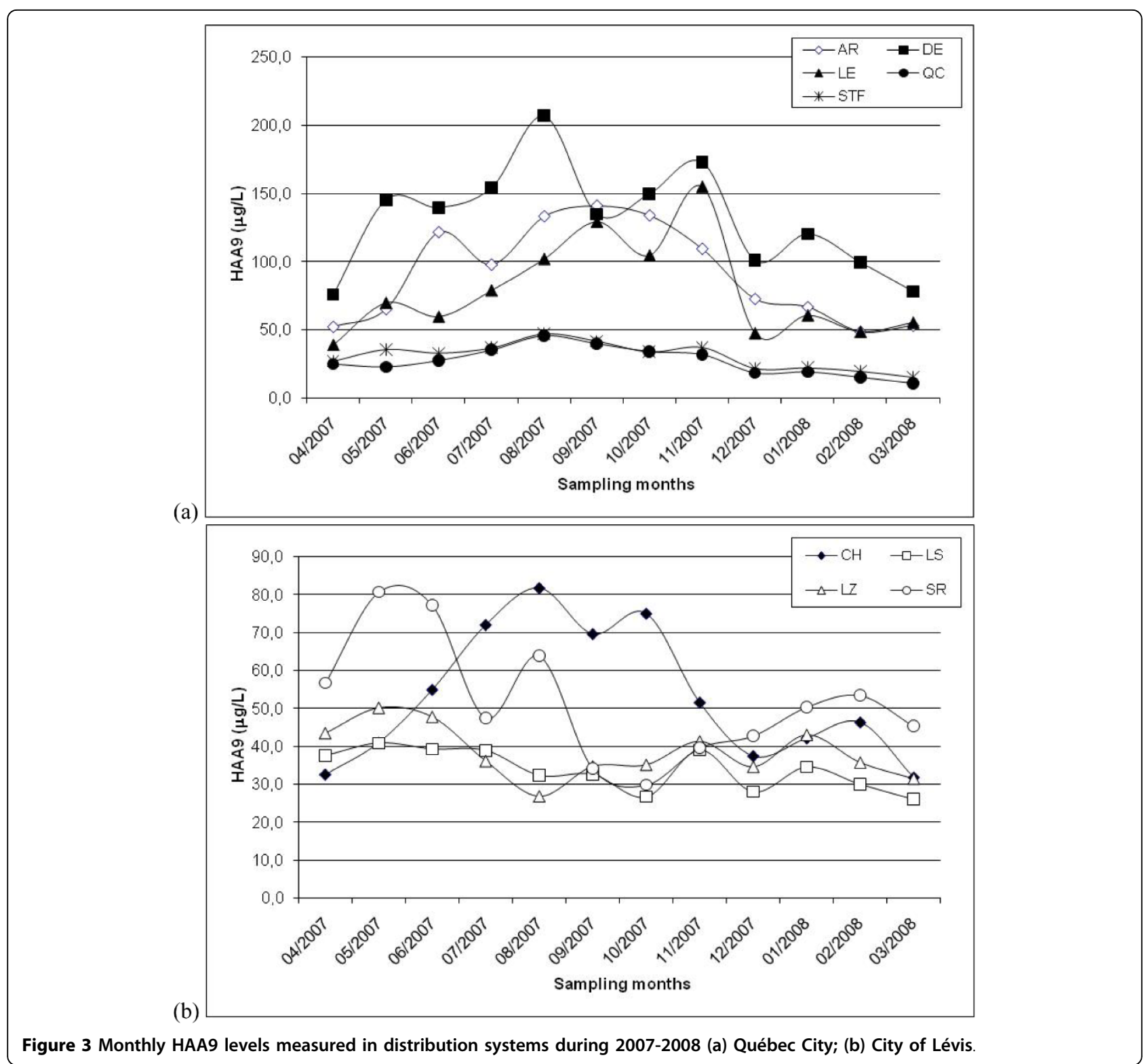

classification between the methods based on one or two sampling sites (whatever the scale considered) and the method based on system-wide sampling (method F).

The results from the methods applied at the sub-system scale were relatively similar with $\kappa$ values above 0.92 for TTHMs and 0.90 for HAA9 (Table 3). These results show that the spatial variability of CBP occurrence within sub-systems has a small impact on the exposure classification when the entire area under study is considered. The small number of sampling sites for most sub-systems could also explain these results (rarely $>2$ ). Considering the entire area under study, the selection of one method among the four methods at the subsystem scale had little impact on the classification of the subjects in CBP exposure categories. $\kappa$ values from the comparison between the two methods based on the closest sampling site, but at a different scale (i.e., considering only the sub-system for method $\mathrm{C}$ and the entire system for method E), were 0.90 for both TTHMs and HAA9. As a result, when the entire region under study was considered, the closest sampling site in the system of the subject's residence was generally representative of the water quality of the direct water supply infrastructure (e.g., re-chlorination station or the water treatment plant).

In this section, the six exposure assessment methods were compared on the basis of the entire area under study (the nine systems considered together). Thus, the spatial variability of CBP occurrence within specific systems was not taken into account. Since the TTHM and 


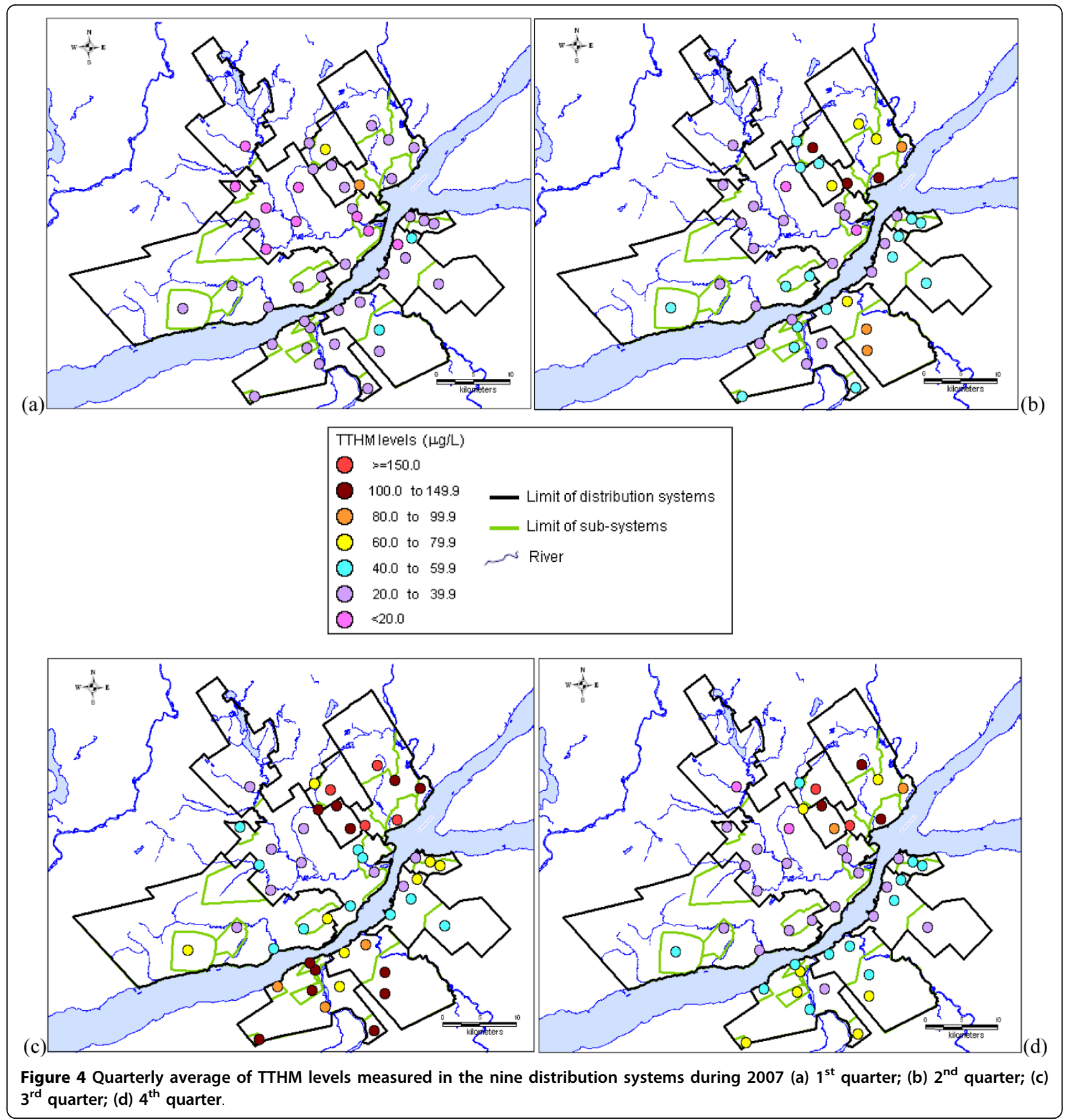

exposure categories were based on levels measured in the entire area, the differences in the range of measured CBP levels between systems could bring about a bias on the observed impact of the assignment method.

\section{Comparison of methods for each individual distribution} system

In order to classify the subject's exposure with each method, four exposure categories were created for each distribution system according to quartiles of CBP levels measured in the specific systems (Table 2). Tables 4 and 5 present for each distribution system, the $\kappa$ values corresponding to the comparison of the classification of the subject's exposure to TTHM and HAA9 obtained from the six methods.

For the AR, CH, DE, LZ and STF systems, high $\kappa$ values were observed for the classification of subject's exposure to TTHM obtained from methods applied at the sub-system scale (Tables 4 and 5). For the DE and 


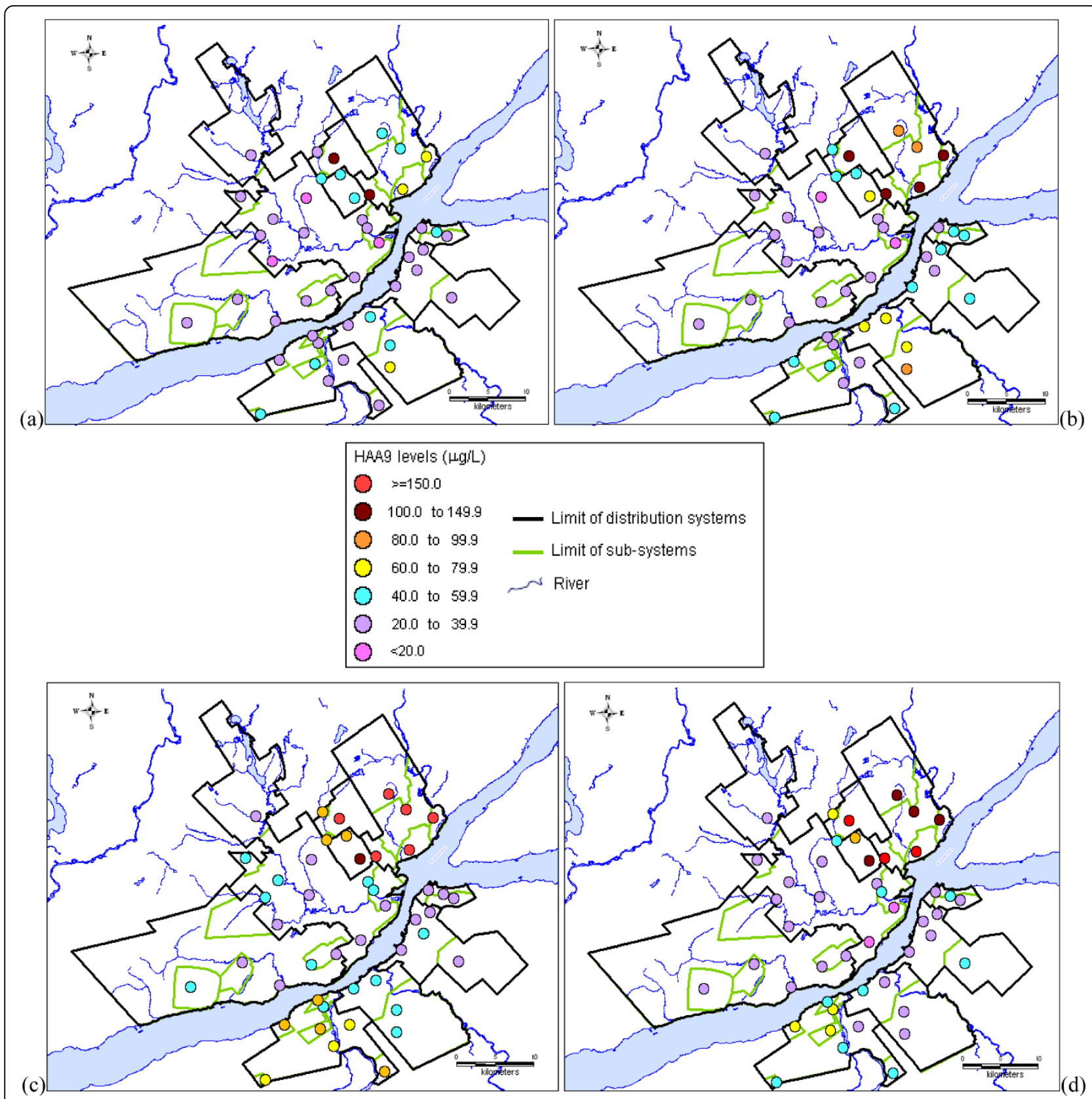

Figure 5 Quarterly average of HAA9 levels measured in the nine distribution systems during 2007 (a) $1^{\text {st }}$ quarter; (b) $2^{\text {nd }}$ quarter; (c) $3^{\text {rd }}$ quarter; (d) $4^{\text {th }}$ quarter.

Table $3 \kappa$ values for the subject's classification in the CBP exposure categories obtained from the six assignment methods considering the entire area under study

\begin{tabular}{|c|c|c|c|c|c|c|c|c|c|c|c|c|c|c|c|}
\hline \multirow[t]{3}{*}{ CBP studied } & \multicolumn{7}{|c|}{ Comparison of methods applied at the same space scale } & \multicolumn{8}{|c|}{ Comparison of methods applied at a different space scale } \\
\hline & \multicolumn{6}{|c|}{ Sub-system } & \multicolumn{9}{|c|}{ System } \\
\hline & A-B & A-C & A-D & B-C & B-D & C-D & E-F & A-E & B-E & C-E & D-E & A-F & B-F & $\mathrm{C}-\mathrm{F}$ & D-F \\
\hline TTHM & 0.98 & 0.94 & 0.95 & 0.92 & 0.96 & 0.92 & 0.72 & 0.86 & 0.84 & 0.90 & 0.82 & 0.74 & 0.75 & 0.71 & 0.77 \\
\hline HAA9 & 0.97 & 0.95 & 0.93 & 0.92 & 0.94 & 0.90 & 0.70 & 0.86 & 0.83 & 0.90 & 0.81 & 0.73 & 0.73 & 0.70 & 0.72 \\
\hline
\end{tabular}


Table $4 \kappa$ values for the subject's classification in the TTHM exposure categories obtained from the six assignment methods for each distribution system

\begin{tabular}{cccccccccccccccc}
\hline \multicolumn{10}{c}{ System name } & \multicolumn{10}{c}{ Comparison of methods applied at the same space scale } & \multicolumn{1}{c}{ Comparison of methods applied at a different space scale } \\
\hline & \multicolumn{1}{c}{ A-B } & A-C & A-D & B-C & B-D & C-D & E-F & A-E & B-E & C-E & D-E & A-F & B-F & C-F & D-F \\
\hline AR & 1.00 & 1.00 & 1.00 & 1.00 & 1.00 & 1.00 & 0.07 & 0.63 & 0.63 & 0.63 & 0.63 & 0.02 & 0.09 & 0.09 & 0.09 \\
\hline CH & 0.98 & 0.96 & 0.98 & 0.94 & 1.00 & 0.94 & 0.66 & 0.86 & 0.84 & 0.90 & 0.84 & 0.64 & 0.64 & 0.65 & 0.64 \\
\hline DE & 1.00 & 1.00 & 1.00 & 1.00 & 1.00 & 1.00 & 0.56 & 0.82 & 0.82 & 0.82 & 0.82 & 0.52 & 0.52 & 0.52 & 0.52 \\
\hline LZ & 0.99 & 0.97 & 0.99 & 0.96 & 1.00 & 0.96 & 0.22 & 0.71 & 0.70 & 0.74 & 0.70 & 0.12 & 0.13 & 0.14 & 0.13 \\
\hline STF & 1.00 & 1.00 & 1.00 & 0.99 & 1.00 & 0.99 & 0.52 & 0.58 & 0.58 & 0.59 & 0.58 & 0.39 & 0.39 & 0.39 & 0.39 \\
\hline LE & 0.93 & 0.85 & 0.93 & 0.78 & 1.00 & 0.78 & 0.78 & 0.85 & 0.78 & 1.00 & 0.78 & 0.93 & 1.00 & 0.78 & 1.00 \\
\hline SR & 0.94 & 0.92 & 0.94 & 0.85 & 1.00 & 0.85 & 0.61 & 0.90 & 0.84 & 0.98 & 0.84 & 0.58 & 0.58 & 0.60 & 0.58 \\
\hline LS & 0.79 & 0.70 & 0.43 & 0.50 & 0.47 & 0.37 & 0.27 & 0.70 & 0.50 & 1.00 & 0.37 & 0.34 & 0.38 & 0.27 & 0.81 \\
\hline QC & 0.92 & 0.87 & 0.77 & 0.79 & 0.80 & 0.72 & 0.51 & 0.82 & 0.77 & 0.89 & 0.67 & 0.57 & 0.60 & 0.52 & 0.71 \\
\hline
\end{tabular}

AR systems, $\kappa$ values were due to the presence of a single sampling location per sub-system. In the case of the $\mathrm{CH}, \mathrm{LZ}$ and STF systems, the high reliability between the methods was associated with the low variability of TTHM occurrence within sub-systems which is generally due to their small size. However, the relative structural complexity of these systems involves important TTHM level variations within the entire system (i.e., between the sub-systems). As a result, important differences between the system-wide average method (method F) and the five other methods were observed ( $\kappa$ values < $0.10)$. As shown in Table 5 , a similar pattern was observed for HAA9 with a different intensity according to the system.

Since the LE system consists of a single system, methods $C$ and $E$ are similar (same thing for methods D and F). In order to facilitate the result analysis, only methods A to $\mathrm{D}$ were compared for this system. The $\kappa$ values obtained from the comparison between these four methods show a slight impact of the method on the classification of the subject's exposure to TTHMs and HAA9. These results are probably due to the structural simplicity of this system (one sub-system) and to the low variations of CBPs within this system.

The SR and LS systems include two different sub-systems (one directly supplied by the water treatment plant and the other supplied by a re-chlorination station) which involve spatial variations of TTHMs and HAA9 in the entire system. As shown in Tables 4 and 5, these variations have an impact on the classification of the subject's exposure according to the method applied. For example, exposure results with the method based on a single sampling site at the system scale (method E) differed from the results with the method based on the system wide-average (method F). This phenomenon was particularly pronounced for the LS system (Table 4). The impact of spatial variations of TTHM levels within sub-systems on the subject's exposure assessment was also observed for these two systems. In fact, $\kappa$ values below 0.50 for the LS system and of 0.85 for the SR

Table $5 \kappa$ values for the subject's classification in the HAA9 exposure categories obtained from the six assignment methods for each distribution system

\begin{tabular}{|c|c|c|c|c|c|c|c|c|c|c|c|c|c|c|c|}
\hline \multirow[t]{3}{*}{ System name } & \multicolumn{7}{|c|}{ Comparison of methods applied at the same space scale } & \multicolumn{8}{|c|}{ Comparison of methods applied at a different space scale } \\
\hline & & & Sub & stem & & & System & & & & & & & & \\
\hline & A-B & A-C & A-D & B-C & B-D & C-D & E-F & A-E & B-E & C-E & D-E & $A-F$ & B-F & $\mathrm{C}-\mathrm{F}$ & D-F \\
\hline$A R$ & 1.00 & 1.00 & 1.00 & 1.00 & 1.00 & 1.00 & 0.14 & 0.61 & 0.61 & 0.61 & 0.61 & 0.13 & 0.13 & 0.13 & 0.13 \\
\hline $\mathrm{CH}$ & 0.98 & 0.95 & 0.98 & 0.92 & 1.00 & 0.92 & 0.54 & 0.80 & 0.78 & 0.85 & 0.78 & 0.54 & 0.55 & 0.55 & 0.55 \\
\hline $\mathrm{DE}$ & 1.00 & 1.00 & 1.00 & 1.00 & 1.00 & 1.00 & 0.45 & 0.83 & 0.83 & 0.83 & 0.83 & 0.45 & 0.45 & 0.45 & 0.45 \\
\hline LZ & 0.98 & 0.95 & 0.98 & 0.93 & 1.00 & 0.93 & 0.35 & 0.68 & 0.66 & 0.72 & 0.66 & 0.37 & 0.36 & 0.35 & 0.36 \\
\hline STF & 0.99 & 0.97 & 0.99 & 0.96 & 1.00 & 0.96 & 0.35 & 0.46 & 0.45 & 0.49 & 0.45 & 0.31 & 0.32 & 0.30 & 0.32 \\
\hline LE & 0.91 & 0.84 & 0.91 & 0.75 & 1.00 & 0.75 & 0.75 & 0.84 & 0.75 & 1.00 & 0.75 & 0.91 & 1.00 & 0.75 & 1.00 \\
\hline SR & 0.93 & 0.90 & 0.93 & 0.83 & 1.00 & 0.83 & 0.79 & 0.88 & 0.82 & 0.98 & 0.82 & 0.84 & 0.86 & 0.79 & 0.86 \\
\hline LS & 0.86 & 0.84 & 0.73 & 0.70 & 0.80 & 0.60 & 0.31 & 0.84 & 0.70 & 1.00 & 0.60 & 0.37 & 0.39 & 0.31 & 0.44 \\
\hline QC & 0.91 & 0.83 & 0.75 & 0.74 & 0.76 & 0.67 & 0.32 & 0.78 & 0.70 & 0.85 & 0.62 & 0.43 & 0.45 & 0.31 & 0.48 \\
\hline
\end{tabular}


system were obtained from the comparison at the subsystem scale between the method using a single sampling site (method $C)$ and the methods using two or more sampling sites without distance factor (methods B and D). A comparable pattern was observed for HAA9.

As shown in Tables 4 and 5 , the space scale has an impact on the classification of the subject's exposure in the QC system with relatively low levels of agreement between the methods at the sub-system scale and the methods at the system scale. The differences obtained between the four methods at the sub-system scale demonstrate the influence of the proximity on the subject's classification in the QC system. However, as shown in Table 2, CBP levels measured in the QC system were relatively low. As a result, differences observed between the methods could be due primarily to the low range of CBP levels and may not reflect the real impact of the method applied to the subject's exposure assessment.

For each of the nine distribution systems under study, important differences were observed between the subject's exposure classification in the two methods based on the closest sampling site, but at a different space scale (methods $\mathrm{C}$ and $\mathrm{E}$ ). As a result, the sampling site that considers the entire system might not be representative of the water quality from the direct subject's supply infrastructure (e.g., re-chlorination station) and could induce misclassification for CBP exposure estimation. As shown in Tables 4 and 5, the level of agreement between methods $C$ and $E$ varies according to the spatial variability of TTHM and HAA9 levels in the distribution system.

\section{Conclusions}

This paper shows that the spatial approach applied to assign TTHM and HAA9 data to subjects has an important impact on exposure assessment results. The nonconsideration of this variability in the assessment of CBP levels in the subject's drinking water could result in exposure misclassification.
According to the results obtained in this study, some recommendations can be made to improve the assessment of the subject's exposure based on available TTHM and HAA9 data in epidemiological studies and thus to minimize exposure misclassification (Table 6). These recommendations are adapted according to the spatial variability of CBP occurrence within systems (which could be estimated through available data from other studies or from regulatory surveys) and to the type of data available. As shown in this study, the spatial variability of CBPs differs according to systems (influence of the treated water quality and system structure). As a result, the approach used to assign available CBP data to subjects should be specific to each system. Moreover, specific considerations should be afforded to each CBP class under study.

In this study, the number of sampling sites per subsystem differed according to the system. This could affect the comparison of the classification of the subject's exposure to CBP (obtained from each method) between systems. Moreover, only spatial aspects were considered in the assignment of CBP data to subjects. However, as shown in Section 3.1, the considerable temporal variability of THMs and HAAs was also demonstrated. This temporal aspect should be considered in the assessment of the CBP levels in the subject's drinking water, particularly in the case where short-term exposure periods are studied (e.g., studies on adverse reproductive outcomes).

THMs and HAAs are not always correlated with other CBP compounds [32]. As a result, the relevance of their use as markers of CBP exposure could be questioned. In future studies, the assessment of population exposure to CBPs in drinking water assessment should include the measurement of other CBPs (e.g., haloacetonitriles, haloketones) [1]. Since the mechanisms of toxic action differ from one compound of the same CBP class to another (e.g., individual THMs or HAAs), the effect of individual CBPs should be investigated [33-35]. Future research should also focus on the effects of the mixtures of CBPs in drinking water on human health $[32,33]$.

Table 6 Recommendations to spatially assign the available CBP data to the subjects in epidemiological studies

\begin{tabular}{clll}
\hline $\begin{array}{c}\text { Degree of spatial } \\
\text { variability of CBP levels } \\
\text { in the system }\end{array}$ & \multicolumn{1}{c}{ Number of CBP data available for the distribution system under study } \\
\hline & $\begin{array}{l}\text { 1 site/sub- } \\
\text { system }\end{array}$ & $>$ 1 site/sub-system & $\begin{array}{l}>\text { 1 site/distribution system (but not sampling site in } \\
\text { each sub-system) }\end{array}$ \\
\hline High & $\begin{array}{l}\text { Use of the } \\
\text { sampling site in } \\
\text { sub-system }\end{array}$ & $\begin{array}{l}\text { The closest sampling site from the } \\
\text { subject's residence }\end{array}$ & $\begin{array}{l}\text { Determination of comparable sub-systems. Use of the } \\
\text { sampling site located in sub-system with the most } \\
\text { similar characteristics. }\end{array}$ \\
\hline Low & $\begin{array}{l}\text { Use of the } \\
\text { sampling site in } \\
\text { sub-system }\end{array}$ & $\begin{array}{l}\text { Average of all sampling sites or average } \\
\text { of the two closest sites from the subject's } \\
\text { residence }\end{array}$ & \begin{tabular}{l} 
Similar to above or average of all sampling sites \\
\hline
\end{tabular} \\
\hline
\end{tabular}




\section{List of abbreviations}

BDCM: Bromodichloromethane; BCAA: Bromochloroacetic acid; BDCAA Bromodichloroacetic acid; CBP: Chlorination by-products; DBCAA: Dibromochloroacetic; DBCM: Dibromochloromethane; DBAA: Dibromoacetic acid; DCAA: Dichloroacetic acid; GIS: Geographical information system; HAA: Haloacetic acids; HAA 9: Sum of the nine haloacetic acids; IUGR: Intrauterine growth retardation; MCAA: Monochloroacetic acid; MBAA: Monobromoacetic acid; PERC.: Percentile; SAS: Statistical analysis system; SD: Standard deviation; SPSS: Statistical package for the social sciences; TBAA: Tribromoacetic acid; TCAA: Trichloroacetic acid; THM: Trihalomethanes; TTHM: Total trihalomethanes; US: United states; WF: Weighting factor.

\section{Competing interests}

The authors declare that they have no competing interests.

\section{Authors' contributions}

$\mathrm{CL}$ conceived and designed the study, collected the data, performed the statistical analysis, interpreted the data and drafted the manuscript; MJR contributed to conception of the study and its design, supervised the study and helped to draft the manuscript, JBS and PL contributed to conception of study and helped to interpret the data. All authors read and revised the final manuscript.

\section{Acknowledgements}

The authors extend their gratitude to the Canadian Institute of Health Research (CIHR), the Drinking Water Research Chair of Université Laval (Quebec City, Canada) and its partners (NSERC, Cities of Quebec and Levis, ITF-Labs-Avensys and Dessau) for their financial support of this research. The authors are also grateful to Sabrina Simard, Sylvie Leduc and Sonia Poulin for their laboratory and field technical support.

\section{Author details}

'École supérieure d'aménagement du territoire, Université Laval, Pavillon Antoine Savard, Québec City, QC., G1K 7P4, Canada. ²Département de Génie Civil, Université Laval, 2917B Pavillon Pouliot, Québec City, QC., G1K 7P4, Canada. Institut National de Santé Publique du Québec, 945 Avenue Wolfe, Québec City, QC., GIV 5B3, Canada.

Received: 22 March 2010 Accepted: 7 October 2010

Published: 7 October 2010

\section{References}

1. Nieuwenhuijsen MJ: Adverse reproductive health effects of exposure to chlorination disinfection by products. Global Nest 2005, 7:128-144.

2. Tardiff RG, Carson ML, Ginevan ME: Updated weight of evidence for an association between adverse reproductive and developmental effects and exposure to disinfection by-products. Regul Toxicol Pharmacol 2006, 45:185-205.

3. Villanueva CM, Fernandez F, Malats N, Grimalt JO, Kogevinas M: Metaanalysis of studies on individual consumption of chlorinated drinking water and bladder cancer. Journal of Epidemiology and Community Health 2003, 57:166-173.

4. Hrudey SE: Chlorination disinfection by-products, public health risk tradeoffs and me. Water Res 2009, 43:2057-2092.

5. Bove F, Shim Y, Zeitz P: Drinking water contaminants and adverse pregnancy outcomes: A review. Environ Health Perspect 2002, 110:61-74.

6. Reif JS, Hatch MC, Bracken M, Holmes LB, Schwetz BA, Singer PC: Reproductive and developmental effects of disinfection by-products in drinking water. Environ Health Perspect 1996, 104:1056-1061.

7. Arbuckle TE, Hrudey SE, Krasner SW, Nuckols JR, Richardson SD, Singer P, Mendola P, Dodds L, Weisel C, Ashley DL, Froese KL, Pegram RA, Schultz IR, Reif J, Bachand AM, Benoit FM, Lynberg M, Poole C, Waller K: Assessing exposure in epidemiologic studies to disinfection by-products in drinking water: Report from an international workshop. Environ Health Perspect 2002, 110:53-60.

8. Rodriguez MJ, Serodes JB, Levallois P: Behavior of trihalomethanes and haloacetic acids in a drinking water distribution system. Water Res 2004, 38:4367-4382

9. Dodds L, King W, Woolcott C, Pole J: Trihalomethanes in public water supplies and adverse birth outcomes. Epidemiology 1999, 10:233-237.
10. Gallagher MD, Nuckols JR, Stallones L, Savitz DA: Exposure to trihalomethanes and adverse pregnancy outcomes. Epidemiology 1998, 9:484-489.

11. Lewis $\mathrm{C}$, Suffet $\mathbb{I H}$, Ritz B: Estimated effects of disinfection by-products on birth weight in a population served by a single water utility. Am J Epidemiol 2006, 163:38-47.

12. Porter CK, Putnam SD, Hunting KL, Riddle MR: The effect of trihalomethane and haloacetic acid exposure on fetal growth in a Maryland county. Am J Epidemiol 2005, 162:334-344.

13. Waller K, Swan SH, DeLorenze G, Hopkins B: Trihalomethanes in drinking water and spontaneous abortion. Epidemiology 1998, 9:134-140.

14. Wright JM, Schwartz J, Dockery DW: The effect of disinfection by-products and mutagenic activity on birth weight and gestational duration. Environ Health Perspect 2004, 112:920-925.

15. Bove FJ, Fulcomer MC, Klotz JB, Esmart J, Dufficy EM, Savrin JE: Public Drinking-Water Contamination and Birth Outcomes. Am J Epidemiol 1995, 141:850-862.

16. Klotz JB, Pyrch LA: Neural tube defects and drinking water disinfection by-products. Epidemiology 1999, 10:383-390.

17. Hinckley AF, Bachand AM, Reif JS: Late pregnancy exposures to disinfection by-products and growth-related birth outcomes. Environ Health Perspect 2005, 113:1808-1813.

18. Gouvernement du Québec: Loi sur la qualité de l'environnement L.R.Q, c. Q-2, Juin 2001, Règlement sur la qualité de l'eau potable du Québec, révisé en juin 2005, c. Q-2, r.18.1.1. Gouvernement du Québec 2005

19. Union Européenne: Directive du Conseil de l'Union Européenne $n^{\circ} 98 / 83$ / CE du 3 novembre 1998 relative à la qualité des eaux destinées à la consommation humaine. JOCE $n^{\circ} \mathrm{L} 330$ du 5 décembre 1998 et rectification dans le JOCE $n^{\circ} \mathrm{L} 111$ du 20 avril 2001, Union Européenne 2001.

20. United States Environmental Protection Agency: National Primary Drinking Water Regulations: Disinfectants and Disinfection Byproducts. Washington, DC:: United States Environmental Protection Agency, Office of Ground Water and Drinking Water 1998, 63:69389-69476.

21. Savitz DA, Singer $P C$, Herring AH, Hartmann KE, Weinberg HS, Makarushka C: Exposure to drinking water disinfection by-products and pregnancy loss. Am J Epidemiol 2006, 164:1043-1051.

22. Waller K, Swan SH, Windham G, Fenster L: Influence of exposure assessment method in an epidemiologic study of trihalomethane exposure and spontaneous abortion. Am J Epidemiol 2001, 153:S152-S152.

23. Nuckols JR, Langlois $P$, Lynberg ML, Luben $T$ : Linking geographic water utility data with study participant residences from the National Birth Defects Prevention Study. Denver, CO.: American Water Works Association Research Foundation 2004.

24. Keegan $T$, Whitaker $H$, Nieuwenhuiisen MJ, Toledano MB, Elliott $P$, Fawell J, Wilkinson $\mathrm{M}$, Best $\mathrm{N}$ : Use of routinely collected data on trihalomethane in drinking water for epidemiological purposes. Occup Environ Med 2001, 58:447-452.

25. Rodriguez MJ, Serodes JB, Levallois P, Prouix F: Chlorinated disinfection byproducts in drinking water according to source, treatment, season, and distribution location. Journal of Environmental Engineering and Science 2007, 6:355-365.

26. Dion-Fortier A, Rodriguez MJ, Sérodes J, Proulx F: Impact of water stagnation in residential cold and hot water plumbing on concentrations of trihalomethanes and haloacetic acids. Water Res 2009, 43:3057-3066.

27. SAS Institute Inc: SAS OnlineDoc ${ }^{\oplus}$ 9.1.3. Cary, NC: SAS Institute Inc 2004

28. Cohen J: A Coefficient of Agreement for Nominal Scales. Educational and Psychological Measurement 1960, 20:37-46.

29. Norman G, Streiner D: Measurement of association for categorical data. Biostatistics: The bare essentials B. C. Decker Incorporated, Third 2008, 253-259.

30. Cohen J: Weighted Kappa - Nominal Scale Agreement with Provision for Scaled Disagreement or Partial Credit. Psychological Bulletin 1968, 70:213-220.

31. Landis JR, Koch GG: Measurement of Observer Agreement for Categorical Data. Biometrics 1977, 33:159-174.

32. Bull R, Rice G, Teuschler L, Feder P: Chemical Measures of Similarity Among Disinfection By-Product Mixtures. J Toxicol Env Heal A 2009, 72:482-493. 
33. Richardson SD, Plewa MJ, Wagner ED, Schoeny R, DeMarini DM: Occurence, genotoxicity, and carcinogenicity of regulated and emerging disinfection by-products in drinking water: A review and roadmap for research. Mutation Research 2007, 636:178-242.

34. Health Canada: Guidelines for Canadian Drinking Water Quality: Guideline Technical Document - Trihalomethanes. Ottawa, ON.: Health Canada 2006, 70.

35. Health Canada: Guidelines for Canadian drinking water quality: Guideline technical document - Haloacetic acids. Ottawa, ON.: Health Canada 2008, 82.

doi:10.1186/1476-069X-9-59

Cite this article as: Legay et al: The assessment of population exposure to chlorination by-products: a study on the influence of the water distribution system. Environmental Health 2010 9:59.

Submit your next manuscript to BioMed Central and take full advantage of:

- Convenient online submission

- Thorough peer review

- No space constraints or color figure charges

- Immediate publication on acceptance

- Inclusion in PubMed, CAS, Scopus and Google Scholar

- Research which is freely available for redistribution

Submit your manuscript at www.biomedcentral.com/submit 